\section{ECCOMAS}

Proceedia
COMPDYN 2021

$8^{\text {th }}$ ECCOMAS Thematic Conference on Computational Methods in Structural Dynamics and Earthquake Engineering

M. Papadrakakis, M. Fragiadakis (eds.) Streamed from Athens, Greece, 28 - 30 June 2021

\title{
SIMPLIFIED ANALYSES FOR THE MODEL SETTING OF SCULPTURES: THE “OCEANO" BY GIAMBOLOGNA
}

\author{
Marco Tanganelli ${ }^{1}$, Stefano Galassi ${ }^{1}$ and Stefania Viti $^{1}$ \\ ${ }^{1}$ Department of Architecture (DIDA), University of Florence, \\ via della Mattonaia 14, 50121 Firenze \\ \{stefano.galassi,marco.tanganelli,stefania.viti\}@unifi.it
}

\begin{abstract}
The historical art works represent a priceless asset of communities. Despite their importance, such artifacts are often subjected to many hazards; in Italy, the seismic risk represents one of the most serious dangers which affect the art works, especially those more exposed to overturning. In these years, many studies have been made on the seismic response of artifacts, which evidenced the possible vulnerability of statues to seismic excitations. This paper is focused on the safety assessment of one of the masterpieces of the XVI century art: the marble statue "Oceanus", made by Giambologna in 1570. The sculpture, currently exhibited at the courtyard of the Museo del Bargello in Florence, has a mass of almost 2 tons, and a height of over three meters, and it is the only giant statue made by Giambologna. In the work, a simplified assessment of the seismic response of the sculpture, and of the consequent seismic safety, has been made, by performing a non-linear static analysis. The role plaid by the base restraint and by the pedestal of the sculpture have been checked and discussed. The assessment proposed in the paper is aimed at providing a general comprehension of the dynamic response of the case-study under seismic excitations, and to suggest a proper criterion to set a more detailed model for further analyses.
\end{abstract}

Keywords: Seismic performance of artifacts; artifacts preservation; art works reliability; seismic vulnerability; marble sculptures. 


\section{INTRODUCTION}

Artifacts, at each scale, represent the core of the artistic and cultural identity of communities, and they must be protected against all hazard sources [1-3]. Within artifacts, human-form statues result to be even more vulnerable than others. Beside being subjected to time injuries, they are slender, with an irregular shape and usually made by brittle materials [4]; therefore, they can easily overturn due to horizontal actions. For this reason, the statues result to be very sensitive to the seismic actions, and their capacity to contrast seismic accelerations before overturning has to be carefully checked.

In these last years, many studies have been devoted to the assessment of the vulnerability of statues to horizontal actions. The first contribution to this issue was made by Housner in 1963 [5], with its rigid block analysis, which has been widely developed [6-9]. With the development of the modern techniques of geometrical survey and the consequent possibility to set proper 3D structural models, even the Finite Elements (FE) analysis has been largely adopted for investigating the dynamic response of sculpture to horizontal loading [10-13].

The most suitable method to adopt for predicting the structural behavior of sculptures depends on the contact behavior between them and their supports, and on the expected collapse mechanism. In most cases, marble masterpieces of the Renaissance stand over their pedestal without any specific fixing devices, and therefore their response to horizontal actions are a function of the friction coefficient of the material [14-16]. The proper description of the effective friction at the base of the sculptures requires to adopt proper models and software, able to describe the interface behavior of the object. Furthermore, the effective connection between the artifact and its support is not always known; in many cases, a preliminary study of the quality of the response of the artifact, i.e. the assessment of the most probable collapse mechanism, is essential to correctly drive the choice of the analysis to perform.

In this work, a simplified analysis has been performed to make a quick assessment of the seismic safety of an artifact. Such simplified approach leads to understand if the assessment of the artifact safety is reliable enough; if more comprehensive investigations are needed, it can provide useful information about the choice of the model to use and its setting.

The proposed simplified analysis has been performed on two different models, both defined on the basis of a detailed laser scanner survey. The first model represents the statue as a rigid block, and it leads to investigate its capacity at the overturning. The horizontal action at the overturning has been related to the expected seismic hazard, described through the Technical Code provisions for the area and the foundation soil of the Museum of Bargello, where the statue is placed.

The second model, instead, consists of a FE representation, and provides the amount of stress arising in the case-study under the same assumed seismic excitation. The results provided by the performed analyses have been used to find the Safety Index (SI) of the statue, which has been expressed in term of acceleration, displacement and stress. The SI has been referred to the dynamic response of the sole statue, and of the system made of the statue and its pedestal. The comparison of the obtained results led to have e first assessment of the safety level of the case-study under the expected seismic excitation, and to have useful information to perform further analyses.

\section{THE CASE-STUDY}

Oceanus is a giant statue made by Giambologna between 1572 and 1576 for a Fountain placed in the "Boboli Gardens", next to Palazzo Pitti. The Fountain represented the myth of controlling the waters, as an allegory for good government, and it comprehended even a huge granite basin, roughed out by sculptor and architect Niccolò Tribolo. The Fountain was 
moved in another position within the Boboli Garden, where it is still now; the sculpture of Oceanus was moved to the National Museum of Bargello in 1911, and it was replaced it in the original location by a copy. At the current time, therefore, Oceanus is placed in the Courtyard of the Museum of Bargello, as can be seen in Figure 1.

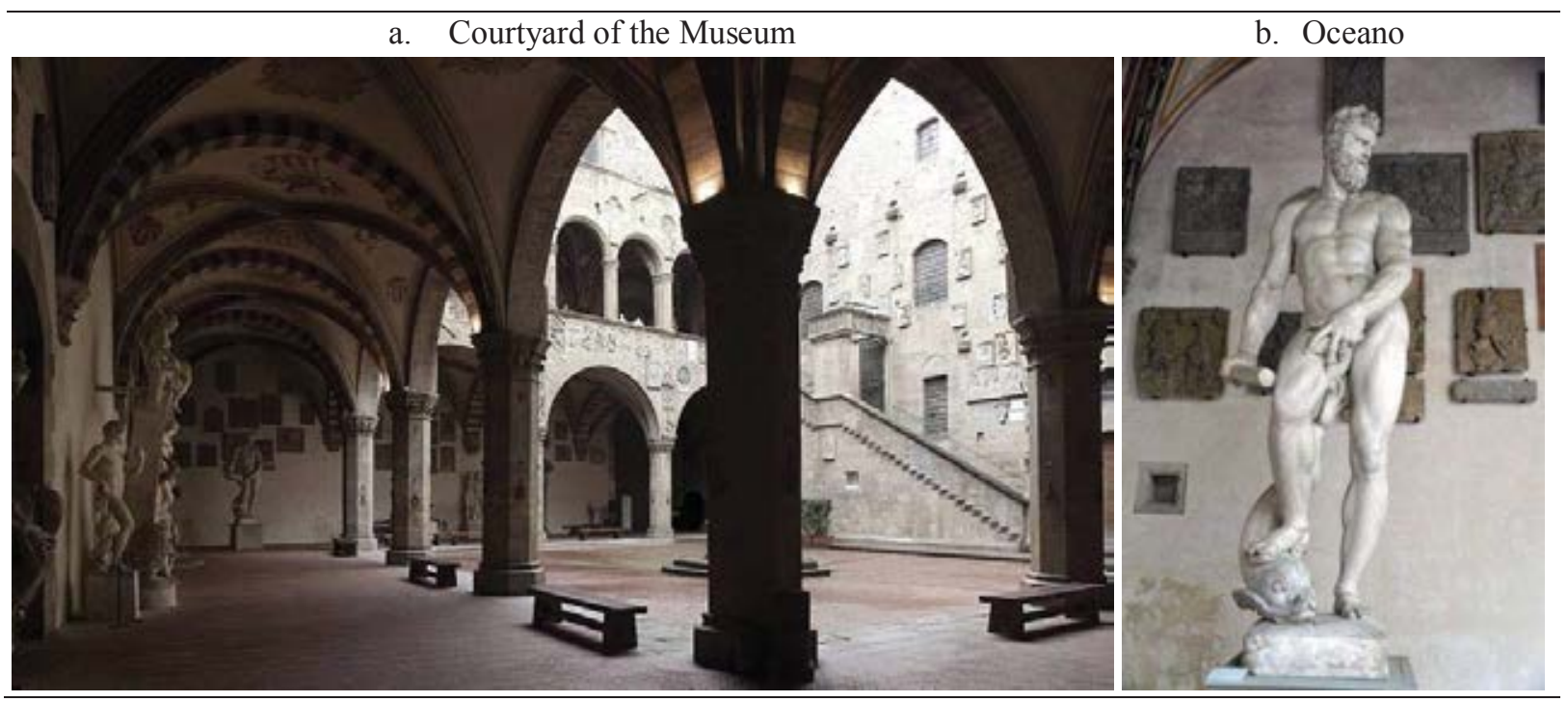

Figure 1. The statue of Oceanus at the Museum of Bargello in Florence

Oceanus (see Figure 2) has an heigh equal to $3.31 \mathrm{~m}$, and a weight of about 2 tons, and it is made of Carrara's marble.

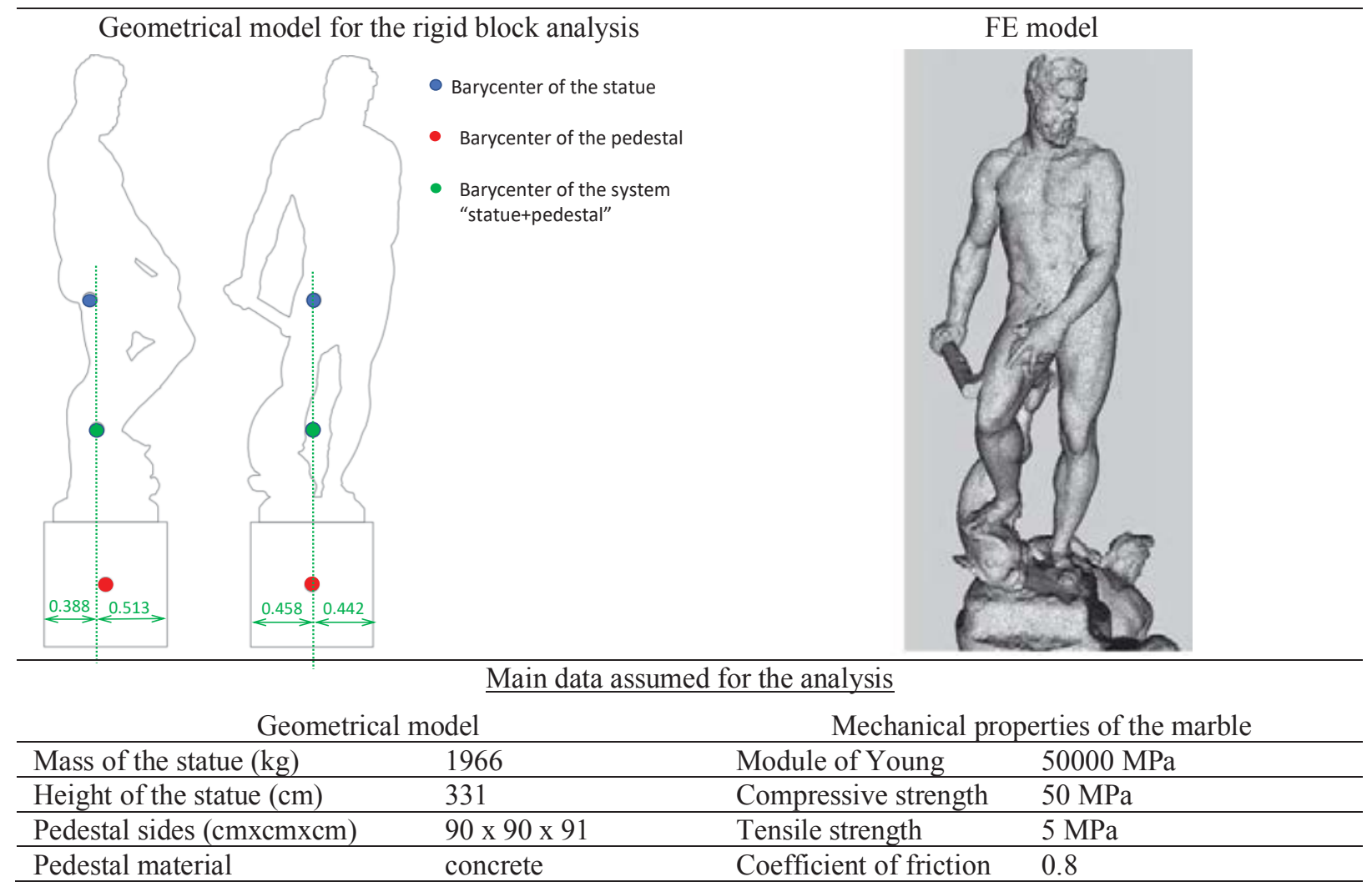

Figure 2. The statue of Oceanus: geometrical and structural models and main data. 
The geometry of the statue has been defined after a detailed laser-scanner survey, which led to define both the equivalent rigid block and the FE model. This latter model has been found from the geometric one through some proper arrangements. The first change consisted in a reduction of the polygons from 2000000 to 103259 , in order to obtain a simpler model, suitable to be used for the structural analysis. Successively, the "surface" model has been changed in "solid" one, by including the area inscribed in its lateral surface. Figure 2 shows the geometry of the sculpture, together with the main information on the geometry. The barycenter has been found with reference to the statue only and to the system made of the statue and the pedestal together. In the same figure, some information regarding the mechanical properties assumed for the material has been shown. Oceanus is made of Carrara's marble; the mechanical properties of the marble have been found after proper experimental investigation $[17,18]$ made on marble samples taken from the Carrara's quarries. A special attention has been paid to the assessment of the friction coefficient $(C F)$. The pedestal of the statue is made of concrete; there is not information regarding the fixing between the statue and the pedestal. In this work, therefore, a $C F$ equal to 0.8 has been assumed, in the hypothesis of lack of specific fixing devices, but assuming a layer of mortar between the statue and the pedestal.

\section{THE SAFETY ASSESSMENT}

\subsection{The preliminary analyses}

Two preliminary analyses have been performed to check the dynamic properties of the statue and the amount of stress arising under gravitational loads only. In both cases, a FE model has been adopted, and a fixed base restraint has been assumed. In Figure 3 the first five Periods of the case-study have been listed, together with the corresponding participating mass and modal shape, and the first two modal shapes are shown.

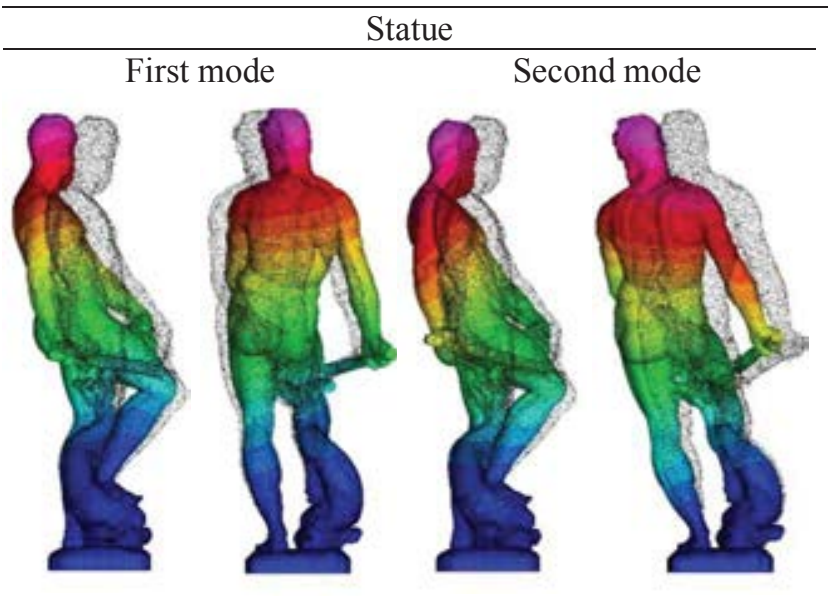

Period Participation Participation Participation (sec) Factor, X (\%) Factor, Y (\%) Factor, Z (\%)

\begin{tabular}{rrrrr}
\hline 1 & 0.074 & 16.472 & 47.638 & 0.166 \\
\hline 2 & 0.045 & 47.723 & 17.469 & 0.633 \\
\hline 3 & 0.019 & 6.774 & 0.442 & 0.005 \\
\hline 4 & 0.011 & 2.969 & 4.578 & 22.287 \\
\hline 5 & 0.008 & 3.442 & 5.195 & 2.796 \\
\hline
\end{tabular}

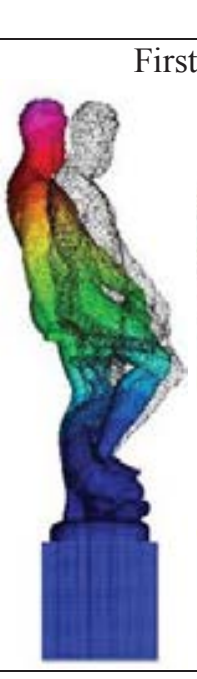

Period Participation Participation Participation (sec) Factor, X (\%) Factor, Y (\%) Factor, Z (\%)

\begin{tabular}{ccccc}
\hline 1 & 0,077 & 9,717 & 26,187 & 0,092 \\
\hline 2 & 0,049 & 27,450 & 10,590 & 0,310 \\
\hline 3 & 0,020 & 3,539 & 0,149 & 0,000 \\
\hline 4 & 0,012 & 1,948 & 4,070 & 11,136 \\
\hline 5 & 0,008 & 2,778 & 5,234 & 0,647
\end{tabular}

Figure 3. Main vibrational periods and modal shapes of the case-study. 
As can be noted, the first mode refers to the $Y$ (front-back of the statue) direction, while the second mode refers to the $X$ (left-right) one. The statue evidences a torsional response even in the first modes. When the pedestal is included in the analysis, the quality of the vibrational modes does not change, but the participation mass of the first modes decreases a lot.

In Figure 4 the distribution of stress experienced by the material under gravitational loads only is shown. As can be observed, the highest stress is gathered in the ankles of Oceanus, which are the narrowest cross sections of the statue. The amount of stress, however, is about 20 times below the elastic limit of the material.

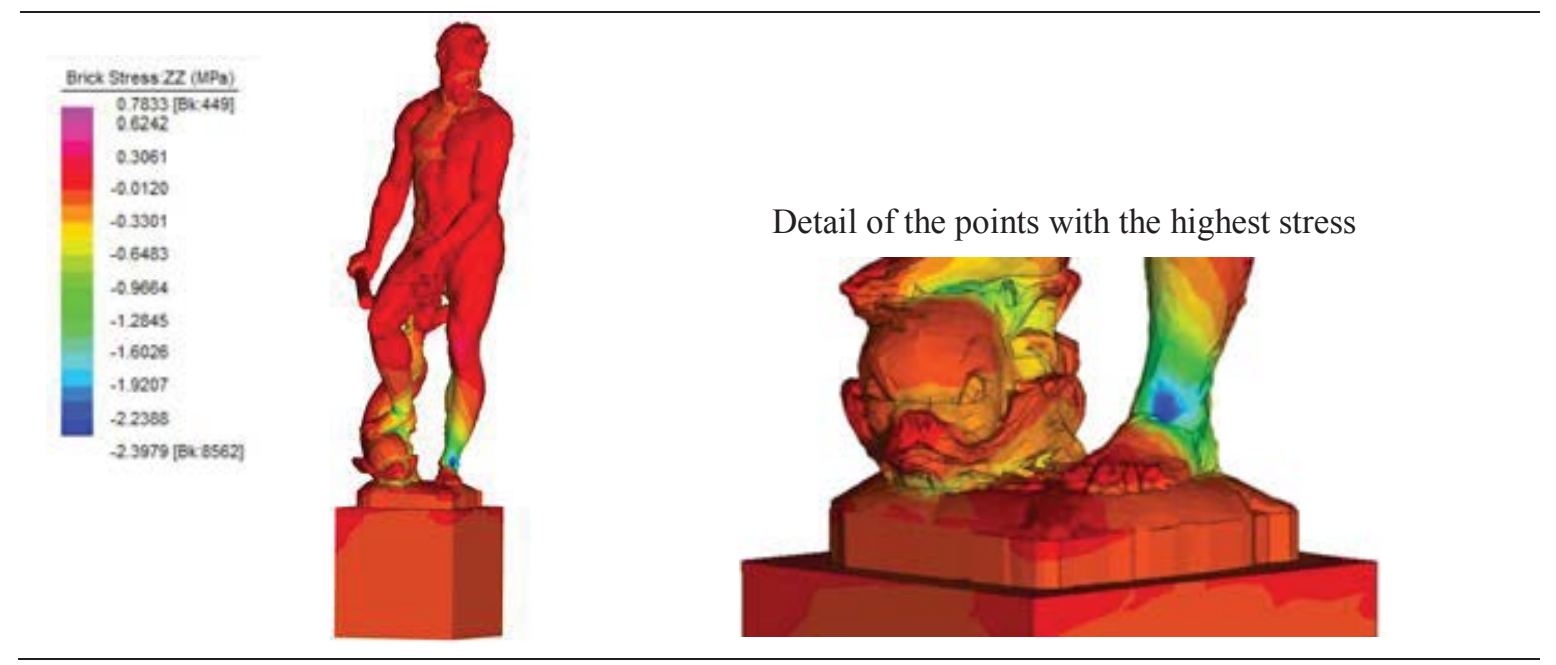

Figure 4. Stress distribution under gravitational loads only.

\subsection{The seismic assessment}

The assessment of the seismic safety of a statue is related to its collapse mechanism. Previous studies made on similar artifacts $[13,19,20]$ found out the overturning to be the most probable collapse mechanism; such prediction, however, cannot be made regardless of the assumed base restraint and of the mass distribution.

When the base-restraint is a simple support, the amount of stress in the material is quite low, and the collapse is related to the displacement experienced by the object. About Oceanus, the type of the base restraint is not known; the simply supported restraint, however, is the most likely to has been adopted. In this work the simplified seismic safety assessment has been made with reference to both the possible base-restraint hypotheses. In both cases, the seismic response of the case-study has been studied both by considering the statue by itself, and integral with its pedestal.

The limit values of the displacement at the overturning have been determined by imposing the equilibrium of the rigid body. The simplified approach proposed by Parisi and Augenti [21] has been applied, and the overturning of the statue has been represented by equalizing the moment demand, defined as the product of the horizontal force applied to the statue centroid and its distance to the turning point, and the corresponding capacity, defined as the product of the sculpture weight and the distance between its centroid the basement side.

Figure 5 shows the top displacement $(T D)$ at the overturning found for the case-study in the two directions, respectively neglecting the pedestal or taking it into account.

The limit horizontal accelerations corresponding to the system overturning have been found by considering the seismic hazard of the area. A soil class B has been assumed for the foundation, according to previous investigations made on the Museum of Bargello [22]. 
The seismic ground acceleration, $A_{g}$, has been assumed equal to $0.1659 \mathrm{~g}$, corresponding to the Life Safety limit state for a class of use $c_{u}=2$, a nominal life equal to 50 years and a Return Period equal to 949 years (Probability of Occurrence of 10\%). The Fundamental Period of the system has been assumed equal to $0 \mathrm{sec}$, i.e. the sculpture has been assumed as perfectly rigid. The amplification factor $\left(f_{a}\right)$, has been found according to the current Code (NTC 2018, [23]):

$$
f_{a}=\frac{a_{0} \times q_{a}}{A_{g} \times S \times C F}
$$

where $a_{0}$ is the acceleration corresponding to the overturning mechanism, $q_{a}$ is the behavior factor, assumed equal to $2, C F$ is the confidence factor, assumed equal to 1 , and $S$, assumed as 1.2 , is the product of the stratigraphic amplification factor and the topographic amplification factor.

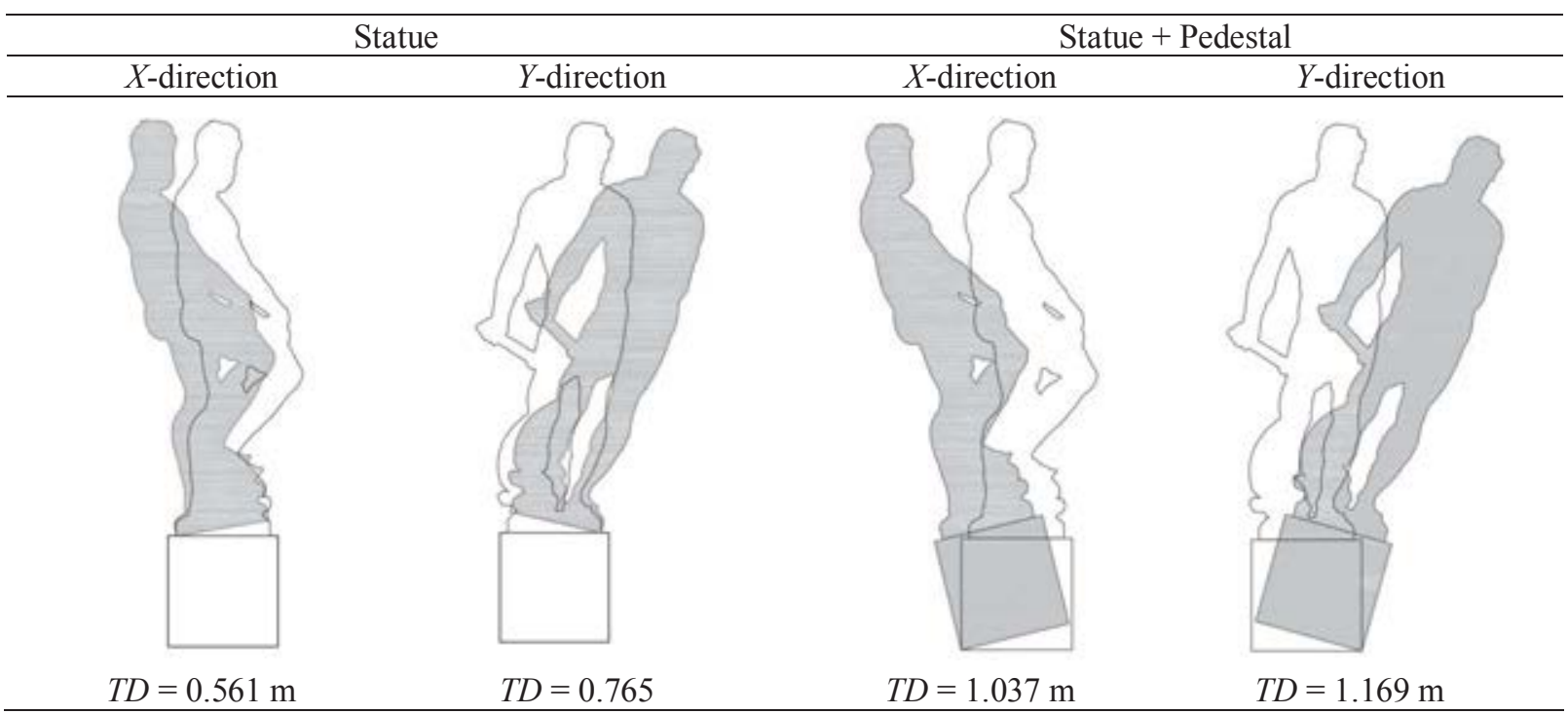

Figure 5. Overturning rotations and Tod Displacements of the case-study.

In Table 1 the values of the overturning acceleration and the amplification factor are listed for the two directions, together with the corresponding Acceleration Safety Index, SI_ACC, defined as $1 / f_{a}$. It is worth noting that the system is safe for $S I A C C$ values below the unity, and that the safety factor of the system is the highest of those provided by the considered cases of analysis.

Table 1. Parameters assumed for defining the seismic demand.

\begin{tabular}{lcccc}
\hline & \multicolumn{2}{c}{ Statue } & \multicolumn{2}{c}{ Statue + Pedestal } \\
\cline { 2 - 5 } & $X$-direction & $Y$-direction & $X$-direction & $Y$-direction \\
\hline Overturning acceleration, $a_{0}$ & 0,229 & 0,166 & 0,279 & 0,245 \\
\hline Amplification Factor, $f_{a}$ & 2.30 & 1.67 & 2.80 & 2.46 \\
\hline Safety Index, $S I$ ACC & 0.43 & 0.60 & 0.36 & 0.41 \\
\hline
\end{tabular}

The safety of the case-study has been assessed even in terms of displacements. Figure 6 shows the main quantities involved in the spectral assessment of the Safety Index expressed in terms of displacement, SI_DISPL, which is defined as the ratio between the displacement demand, of the center of mass, $D_{d}$, and the corresponding ultimate displacement, $D_{u}$ *

The quantity $D_{u}{ }^{*}$, in turn, is defined as the $40 \%$ of $D_{\max }{ }^{*}$, that is the value of the displacement of the barycenter at the overturning. The displacement demand is found as the intersection of the spectral seismic demand (line in green in Figure 6) and the secant Period of the 
system, $T^{*}$, which has been determined according to the expression provided by the current Technical Code (Circ. n. 7, Section C8.7.1.2.1.8, [24]).

As can be noted, the values found for the spectral demand respectively accounting and not for the statue's pedestal are almost coincident; the corresponding ultimate displacements, though, differ significantly from each other; when the performance of the statue is considered without the contribution of its pedestal, its ultimate displacement reduces a lot. In Table 2 the values found for the SI_DISPL have been listed together with the main quantities found for their determination.

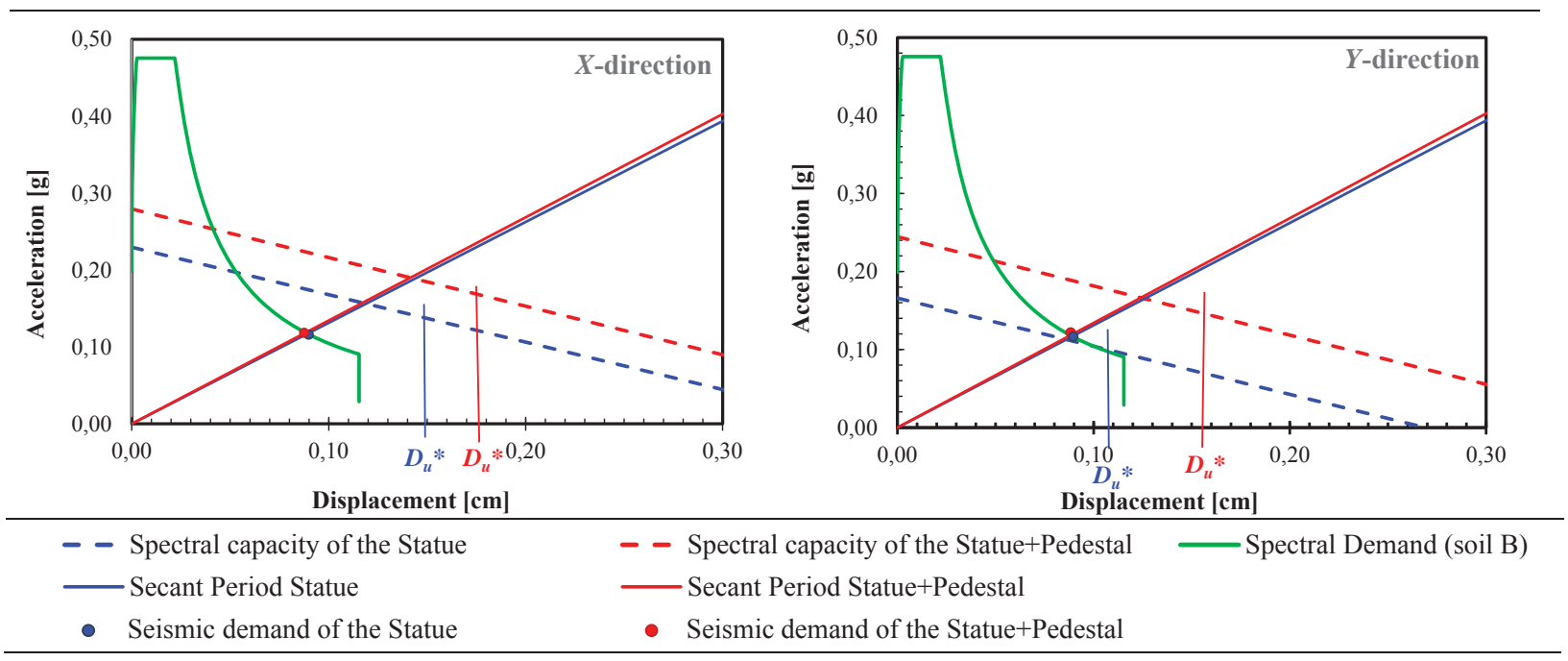

Figure 6. Capacity domains of the case-study along the two main directions.

Table 2. Main quantities used for the safety assessment.

\begin{tabular}{lccccc}
\hline & $D_{\max } *(\mathrm{~cm})$ & $D_{u} *(\mathrm{~cm})$ & $T^{*}(\mathrm{sec})$ & $D_{d}(\mathrm{~cm})$ & $S I$ DISPL \\
\hline Statue, $X$-direction & 37.2 & 14.8 & 1.73 & 8.91 & 0.599 \\
\hline Statue, $Y$-direction & 26.9 & 10.8 & 1.73 & 8.91 & 0.828 \\
\hline Statue + pedestal, $X$ direction & 44.2 & 17.7 & 1.75 & 8.80 & 0.498 \\
\hline Statue + pedestal, $Y$ direction & 38.8 & 15.5 & 1.75 & 8.80 & 0.567 \\
\hline
\end{tabular}

Finally, the seismic safety has been assessed in terms of stress amount. In this case the statue has been assumed to be fixed at the base, since the amount of stress is larger in fixed, i.e. stiffer, systems. Figure 7 shows the stress distribution within the statue found by performing a modal analysis based on the Code spectrum, by using the same seismic input already described in this Session. As can be observed, the larger tensile stress is placed in the back side of the ankles and at the top of the dolphin. The maximum amount of tensile stress is equal to $2.57 \mathrm{MPa}$ and $3.63 \mathrm{MPa}$, respectively, for the sole statue and the statue with the pedestal; since the maximum tensile stress of the marble has been assumed equal to $5 \mathrm{MPa}$, the Safety Index can be expressed in terms of stress (SI_STRESS) as the ratio of the tensile peak and the corresponding capacity.

It is interesting to note that when the pedestal is considered as integral part of the system, the maximum tensile stress is achieved in the front part of the ankles, whilst, when the sole statue is considered, the most tensile points are in the ankles front.

The values of the Safety Index found in terms of acceleration, displacement and stress respectively, have been compared. Figure 8 shows obtained values of SI; as can be observed, all the SI are well below the unit, even if they differ very much from each other. 


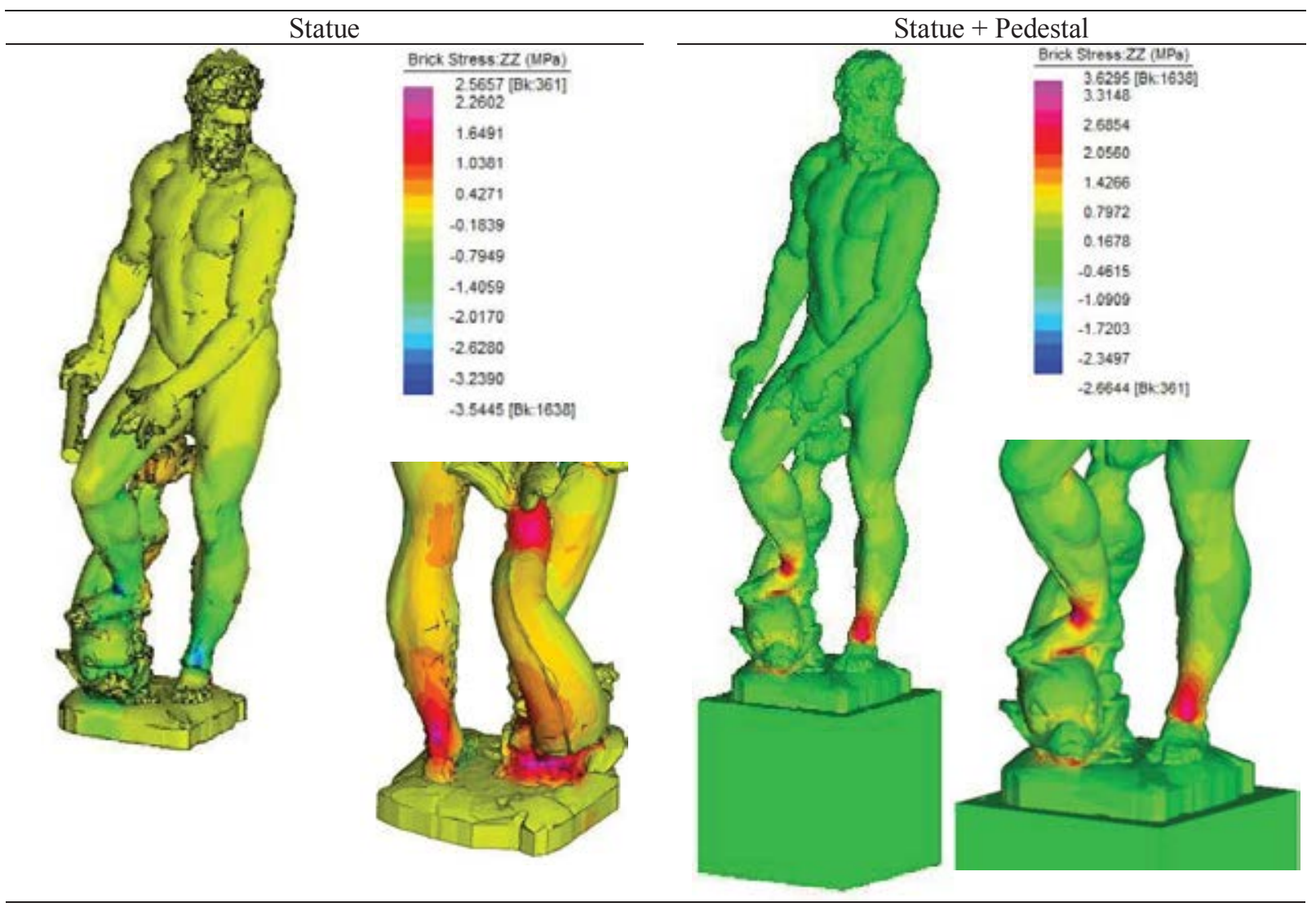

Figure 7. Stress distribution found by performing the modal analysis.

By comparing the values found for the Safety Index, some considerations can be made. First of all, the parameter which is closer to the safety threshold is the displacement; the collapse mechanism to assume for a more comprehensive analysis, therefore, should be the overturning, associated to a simply supported base restraint and a proper mechanical description of the interaction between statue and pedestal. As regards the overturning, when the pedestal is considered as integral to the statue, its contribution improves the performance of the system. The SI_DISPL found for the statue only, however, could not represent the most dangerous seismic response of the system, since it neglects the contribution of the pedestal in the transmission of the seismic action, and/or in the contribution to the total displacement experienced by the statue.

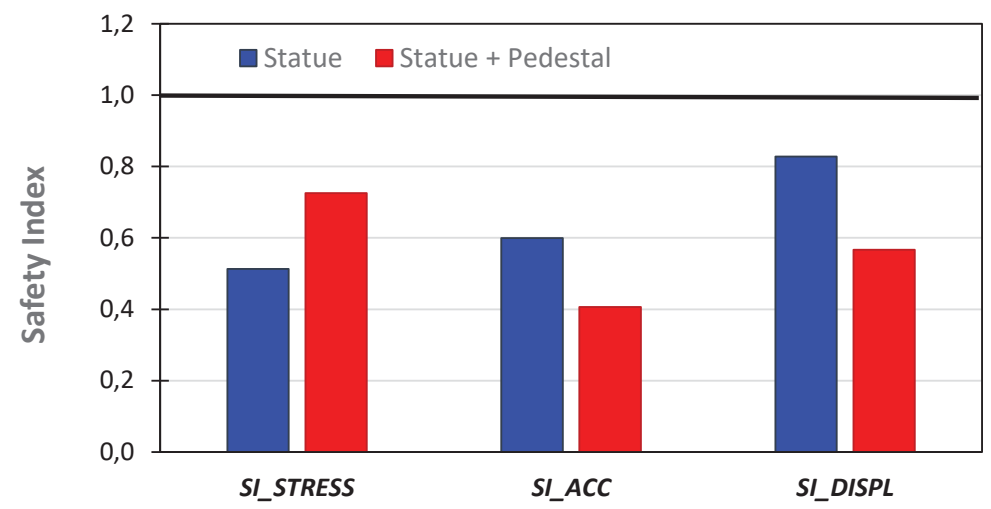

Figure 8. SI values obtained from acceleration, displacement and stress. 


\section{CONCLUSIONS}

In this paper a simplified assessment of the seismic safety of Oceanus, the Renaissance masterpiece made by Giambologna, has been made, applying the simple spectral nonlinear static method. The analyses have been performed by using both a rigid block and a Finite Element models; a special attention has been paid to the role of the pedestal on the seismic response of the case-study and on the restraint condition to assume at the base of the sculpture with reference to the assumed collapse mechanism. Three different Safety Indexes have been found, expressed, respectively, in terms of acceleration, displacement and stress. The analysis states a satisfactory safety level of the statue; however, the differences found between the various Safety Indexes, and the higher value of the SI expressed in terms of displacement comparing to the others, suggest to perform further analyses, checking the nonlinear dynamic response of the statue to seismic excitations, and accounting for the contact behavior between the statue and the pedestal, and between the pedestal and the soil.

\section{REFERENCES}

[1] Lowry MK, Farrar BJ, Armendariz D., and Podany J. (2007). Protecting Collections in the J. Paul Getty Museum from Earthquake Damage. WAAC Newsletter Volume 29.

[2] Spyrakos CC, Maniatakis CA, Taflampas IM (2017). Application of predictive models to assess failure of museum artifacts under seismic loads. Journal of Cultural Heritage $23,11-21$.

[3] Reinhorn AM, Viti S (2020). Monumental buildings used as museums: Protection or danger for the artifacts? Procedia Structural Integrity Vol. 29: pp. 40-47.

[4] Wittich CE, Hutchinson TC, Wood RL, Seracini M, Kuester F (2016). Characterization of Full-Scale, Human-Form, Culturally Important Statues: Case Study J. Comput. Civ. Eng., 30(3).

[5] Housner GW (1963). The behavior of inverted pendulum structures during earthquakes. Bulletin of the Seismological Society of America 53(2)

[6] Monaco M, Guadagnuolo M, Gesualdo A. (2014). The role of friction in the seismic risk mitigation of freestanding art objects. Nat Hazards, 73:389-402.

[7] Kounadis AN. (2015). New findings in the rocking instability of one and two rigid block systems under ground motion. Meccanica, 50:2219-2238.

[8] Bakhtiary E, Gardoni P. (2016). Probabilistic seismic demand model and fragility estimates for rocking symmetric blocks. Engineering Structures 114, 25-34.

[9] Ther T and Kollár, LP (2018). Model for multiblock columns subjected to base excitation. Journal for the International Association for Earthquake Engineering, Edited By: Masayoshi Nakashima, Michael Fardis, and Michael C. Constantinou. Volume47, Issue2: 418-437

[10] Sorace S, Terenzi G. (2015) Seismic performance assessment and base-isolated floor protection of statues exhibited in museum halls, Bull Earthquake Eng, 13, 1873-1892.

[11]Bagnéris M, Cherblanc F, Bromblet P, Gattet E, Gügi L, Nony N, Mercurio V, Pamart A (2017). A complete methodology for the mechanical diagnosis of statue provided by innovative uses of 3D model. Application to the imperial marble statue of Alba-laRomaine (France). Journal of Cultural Heritage, 28:109-116. 
[12]Forcellini D, Giardi F, Tanganelli M (2019). Seismic assessment of the historical third tower in San Marino based on a 3D laser scanner survey (3D-LSS). Innovative Infrastructure Solutions, 4 (1), art. no. 20

[13]Viti S, Pintucchi B, Rotunno T, Tanganelli M (2020). The seismic analysis of Cerere at the Museum of Bargello. Bulletin of Earthquake Engineering, 18(6), pp. 2635-2656, doi: 10.1007/s10518-020-00802-6

[14]Domaneschi M, Tanganelli M, Viti S, Cimellaro GP (2020). Developing a laboratory facility to assess friction coefficients of standing samples. PROCEDIA STRUCTURAL INTEGRITY, vol. 29, p. 142-148, ISSN: 2452-3216, doi: 10.1016/j.prostr.2020.11.150

[15] Tanganelli M, Coli M, Cimellaro GP, Marasco S, Cardoni A, Noori AZ, Viti S (2019). Dynamic analysis of artifacts: experimental tests for the validation of numerical models. In: National Technical University of Athens (NTUA), Proceedings of the 7th International Conference on Computational Methods on Structural Dynamics and Earthquake Engineering. vol. 2, p. 2865-2877, M. Papadrakakis, M. Fragiadakis, ISBN: 978-61882844-7-0, Crete, Greece, 24-26/6/2019

[16] Monaco M, Guadagnuolo M, Gesualdo A (2014). The role of friction in the seismic risk mitigation of freestanding art objects. Natural Hazards (2014) 73: 389-402. DOI: org/10.1007/s11069-014-1076-9.

[17] Viti S, Tanganelli M (2019). Resimus: A research project on the seismic vulnerability of museums' collections. In: (a cura di): M. Papadrakakis M. Fragiadakis, COMPDYN Proceedings. vol. 2, p. 2819-2829, National Technical University of Athens, ISBN: 978618-82844-7-0, grc, 2019.

[18] Tanganelli M Viti S, Cimellaro, GP Domaneschi M (2020). Developing a laboratory facility to assess friction coefficients of standing samples. PROCEDIA STRUCTURAL INTEGRITY, vol. 29, p. 142-148, ISSN: 2452-3216, doi: 10.1016/j.prostr.2020.11.150.

[19]Domaneschi M, Tanganelli M, Viti S, Cimellaro GP (2021). Vulnerability of art works to blast hazard: the Fountain of Neptune in Florence. COMPDYN 2018, Papadrakakis and Fragiadakis Eds.

[20]Domaneschi M, Tanganelli M, Viti S, Cimellaro GP (2021). Protection of art works to blast hazard: the Fountain of Neptune in Florence. International Journal of Masonry Research and Innovation, ArCo2020 New Approaches in Diagnostic and Safety Evaluation of Cultural Heritage.

[21]Parisi F, Augenti N (2013). Earthquake damages to cultural heritage constructions and simplified assessment of artworks. Engineering Failure Analysis 34, 735-760.

[22] Sapia V, Materni V, Giannattasio F, Marchetti M (2018). Esplorazione geofisica del sottosuolo: primi risultati nel centro storico di Firenze. In: RESIMUS: Un progetto rivolto alla vulnerabilità sismica delle opere museale, DIDAPRESS.

[23] NTC 2018 [2018]. Decreto del Ministro delle Infrastrutture 17 gennaio 2018. Aggiornamento delle «Norme tecniche per le costruzioni». Gazzetta Ufficiale della Repubblica Italiana, n. 42 del 20 febbraio 2018, Supplemento Ordinario n. 8.

[24]C.S.LL.PP. 21 gennaio 2019. CIRCOLARE, n. 7: Istruzioni per l'applicazione dell'«Aggiornamento delle "Norme tecniche per le costruzioni"» di cui al decreto ministeriale 17 gennaio 2018. (in Italian). 